\title{
Neonatal Outcomes in High Risk Pregnancies in an Egyptian Tertiary Health Care Center
}

\author{
AMIRA S. DIEB, M.D.*; AMANY IBRAHIM, M.D.** and HALA NABIL, M.D.* \\ The Departments of Obstetrics \& Gynecology* and Pediatrics, The Diabetes, Endocrine \& Metabolism Pediatric Unit (DEMPU), \\ Children Hospital**, Faculty of Medicine, Cairo University
}

\begin{abstract}
Background: Early neonatal morbidity and mortality represents a major problem caused by maternal medical and obstetric risk factors complicated by lack of primary antenatal care. High risk pregnancy is known to negatively affect the neonatal outcomes.
\end{abstract}

Aim of the Work: This study aimed to compare low and high risk pregnancy neonatal outcomes and to test individual maternal risk factors for poor neonatal outcomes.

Patients and Methods: A retrospective study was conducted at a tertiary referral hospital over 6 months. After applying eligibility criteria, 157 high and 125 low risk patients were identified. The neonatal outcome measures were weight, sex, Apgar score at 1 and 5 minutes, respiratory distress, neonatal intensive care unit admission, endotracheal intubation, mechanical ventilation, meconium aspiration and neonatal death.

Results: Neonatal morbidity was higher in high risk group $(p<0.05)$. The Relative Risk of low birth weight, poor Apgar score at 1 minute, respiratory distress, neonatal intensive care unit admission, endotracheal intubation and mechanical ventilation was $8.2,1.85,5.13,6.83,15.37$ and 26.42 respectively emphasizing that prematurity affected early neonatal outcomes.

Conclusion: The main determinants of poor neonatal outcomes were preterm delivery, previous section and hypertensive disorders.

Key Words: Apgar score - High risk pregnancy - Low birth weight - NICU admission and neonatal outcome $R D S$.

\section{Introduction}

HIGH-RISK pregnancy is defined as a risk before, during, or after childbirth that may result in maternal or fetal mortality or morbidity. High risk includes many medical and obstetrical problems. An important strategy in the care of high risk patients is to identify the problems by obtaining a detailed

\footnotetext{
Correspondence to: Dr. Amira S. Dieb, E-Mail: amirasaied2026@gmail.com amirasaied2026@cu.edu.eg
}

medical and obstetric history, proper investigations, treatment, regular follow-up and immediate intervention to ensure best possible outcome for both mother and baby [1].

In Egypt, maternal mortality rates declined to 49/100000 live births in 2015 and still going down due to the disseminated coverage and the judicious use of the antenatal care services. The main causes of death were postpartum hemorrhage (25\%), hypertensive disease (16\%), antepartum hemorrhage $(8 \%)$, sepsis $(8 \%)$ and rapture uterus $(7 \%)$. Additionally neonatal and perinatal mortalities were 14 and 15/1000 live births, respectively; perinatal mortalities were mainly caused by congenital anomalies, prematurity, asphyxia, and a considerable percentage of unknown causes, however, the neonatal deaths were attributed to prematurity, respiratory distress, infections, and unknown causes $[2,3]$.

The majority of preterm birth is unfortunately located in Africa and Asia, where about $85 \%$ of all preterm births occur (31\% and 54\%, respectively), mostly in developing countries $[4,5]$. The causes are thought to be multifactorial including medical conditions of the mother or fetus, genetic effects and environmental exposure, infertility treatment, behavioral factors, social, economic and iatrogenic causes [6]. Premature babies are exposed to many immediate complications including respiratory distress syndrome (RDS), hypothermia, hypoglycemia, jaundice, intraventricular hemorrhage, necrotizing enterocolitis, broncho-pulmonary dysplasia, sepsis and patent ductus arteriosus. Long term morbidities include cerebral palsy, mental retardation and retinopathy of prematurity [7].

Another leading risk factor is preeclampsia which usually leads to termination of pregnancy 
to minimize maternal morbidity and mortality. In pregnancies complicated by preeclampsia, obstetricians must balance the need for achieving inutero fetal maturation with the maternal and fetal risks of continuing pregnancy, including progression to eclampsia, abruptio placentae and HELLP syndrome (Hemolysis, Elevated Liver enzymes, Low Platelets), as well as fetal growth restriction and demise [8].

Women who have a primary cesarean section have a greater than $90 \%$ chance of having a repeat cesarean section. This is attributed to the overall increase in the primary cesarean rates, from $14.6 \%$ in 1996 to $20.3 \%$ in 2005 [9]. A significant number of term infants delivered by elective caesarean section are admitted to neonatal intensive care units each year in the US [10] with the diagnosis of transient tachypnea of the newborn, RDS, severe persistent pulmonary hypertension, hypoxic respiratory failure with higher rates of mechanical ventilation, oxygen therapy, extra corporeal membrane oxygenation, and death [11,12] .

Premature rupture of membranes (PROM); rupture of membranes before onset of labor and preterm premature rupture of membranes; rupture before 37 completed weeks, are associated with high perinatal as well as maternal morbidity [13] Deleterious effects of PROM include chorioamnionitis, cord prolapse, placental abruption and preterm labor leading to various fetal complications like fetal death, neonatal pulmonary hypoplasia, RDS, neonatal sepsis, and intraventricular hemorrhage $[14,15]$.

Antepartum hemorrhage (APH) complicates about $2-5 \%$ of all the pregnancies, with incidence of placenta previa about $0.33 \%$ to $0.55 \%$ [16] and incidence of abruptio placentae about $0.5-1 \%$ [17] The maternal complications in patients with APH are malpresentation, premature labor, postpartum hemorrhage, sepsis, shock and retained placenta. Various fetal complications are premature baby, low birth weight, intrauterine death, congenital malformation and birth asphyxia [18].

Therefore, we aimed to compare low and high risk pregnancy neonatal outcomes and to test each individual maternal risk factor for its association with poor neonatal outcomes.

\section{Patients and Methods}

This retrospective case control study was conducted at a tertiary health care center; at Kasr ElAini Hospital, Cairo University, Egypt, from December 2016 to May 2017. The hospital is a tertiary care center which treats more than 40,000 women as outpatients and inpatients and is one of the major referrals for the management of high risk pregnancies, with a catchment area including the five major Egyptian governorates: Cairo, Giza, Qaliobia, Fayoum and Benisweif. The hospital, located in the capital of Egypt, is characterized by clinical, teaching and research mission. Most of the attendants are from low or middle socioeconomic levels. Three hundred thirty one births were recorded and after application of eligibility criteria, 157 patients were identified as high risk group and 125 patients as low risk group. The data flow chart is shown in Fig. (1).

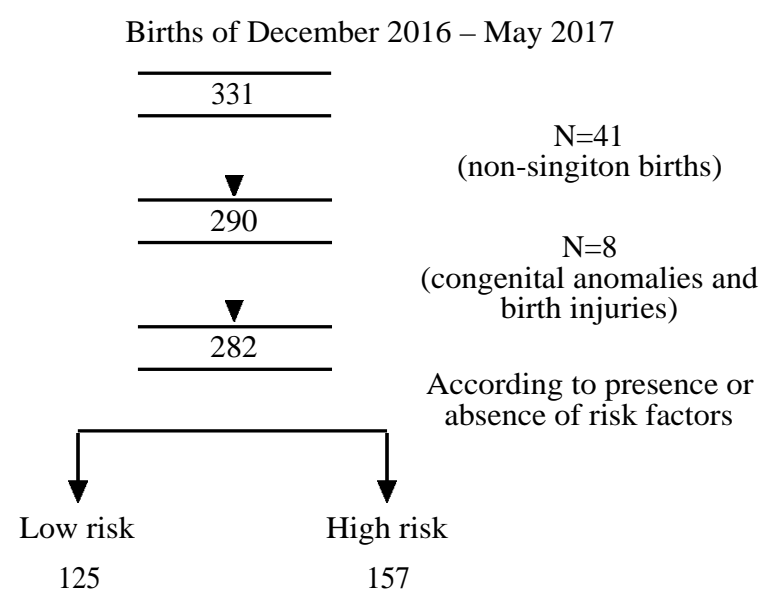

Fig. (1): The Data flow chart of our studied population.

High risk pregnancy was identified by history of medical disorders in the current pregnancy such as hypertension, diabetes mellitus, anemia (hemoglobin $\leq 10.0$ grams), obstetric complications such as preterm labor (deliveries between $24^{+^{\circ}}$ and $36^{+6}$ weeks), antepartum hemorrhage (bleeding after 20 weeks), Premature rupture of membranes (PROM), previous lower segment caesarean section and elderly primigravidas (age greater than 35 years). Low risk pregnancies were all the pregnancies that did not fit the above definition of high-risk. Exclusion criteria were: Multiple pregnancy, congenital anomalies, infections, perinatal asphyxia, chromosomal syndromes and birth trauma. Any abnormalities occurring during pregnancy were registered as well as obstetrical and maternal information.

The data of 157 women with a diagnosed high risk pregnancy and data of their babies were collected and analyzed. The study protocol was approved by the Cairo University's Research Ethical Committee. The data was collected in a database and analyzed as anonymous data for research purpose. 
All deliveries were attended by the neonatologist; details of the resuscitation at the delivery scene were recorded. After delivery, all neonates were admitted to the intermediate care room and subjected to full clinical examination.

The outcome measures used were the neonatal weight, sex, Apgar score at one and five minutes and early neonatal complications as respiratory distress, admission at the neonatal intensive care unit (NICU), endotracheal intubation and AMBU bag, mechanical ventilation, meconium aspiration and neonatal death. The weight of the undressed newborn was measured to the nearest $10 \mathrm{~g}$ by using a standard beam electronic balance (Seca, Hamburg, Germany).

Statistical analysis was performed using MedCalc statistical software for calculating crude relative risk and Minitab software statistical package, version 18.1. Minitab Inc., United States, 2017. Measured data was described as mean and standard deviation (for parametric variables), number and percentage (for categorical variables). Comparison of numerical variables between the study groups was done using Mann Whitney Utest for independent samples. For comparing categorical data, Chi-square $(\chi)$ test was performed. Exact test was used instead when the expected frequency is less than 5. $p$-value $<0.05$ was considered significant.

\section{Results}

Among the study population, 157 patients were identified in high risk group, and 125 patients in low risk group. The mean maternal age was 30.82 \pm 0.46 years in high risk group and $29.47 \pm 0.52$ years in low risk group $(p=0.039)$. In the high risk group 45 patients $(28.66 \%)$ were above the age of 35 , while they represented $24.8 \%$ of low risk group. Of the high risk group 52 patients had medical disorder with pregnancy and 136 patients had obstetric complications including preterm labor. Five of patients were on treatment for medical condition as steroids, low molecular weight heparin and antidepressant. RH negative patients were two in the high risk group and 5 in the low risk group. As regards the mode of delivery, the rate of caesarean section was $94.27 \%$ in the high risk group and $68.8 \%$ in the low risk group $(p<0.001)$. The Apgar score is defined as good score when it is $\geq 7$ and poor score when $<7$. The neonatal birth weight is considered low birth weight if $<2.5 \mathrm{~kg}$. Perinatal outcomes in the two groups are summarized in Table (1).
Table (1): Difference between the neonatal outcomes between the high risk group and the low risk group.

\begin{tabular}{|c|c|c|c|}
\hline $\begin{array}{l}\text { Perinatal outcome } \\
\text { Number }(\%)\end{array}$ & $\begin{array}{c}\text { High risk } \\
(\mathrm{n}=157)\end{array}$ & $\begin{array}{l}\text { Low risk } \\
(\mathrm{n}=125)\end{array}$ & $p$-value \\
\hline \multicolumn{4}{|l|}{ Neonatal sex: } \\
\hline Male & $90(57.3 \%)$ & $66(52.8 \%)$ & 0.448 \\
\hline Female & $67(42.7 \%)$ & $59(47.2 \%)$ & \\
\hline \multicolumn{4}{|l|}{ Neonatal weight: } \\
\hline$\geq 2.5 \mathrm{~kg}$ & $122(77.7 \%)$ & $117(93.6 \%)$ & $<0.001 *$ \\
\hline$<2.5 \mathrm{~kg}$ & $35(22.3 \%)$ & $8(6.4 \%)$ & \\
\hline \multicolumn{4}{|l|}{ Apgar score 1 minute: } \\
\hline$\geq 7$ good score & $111(70.7 \%)$ & $94(75.2 \%)$ & 0.4 \\
\hline$<7$ poor score & $46(29.3 \%)$ & $31(24.8 \%)$ & \\
\hline \multicolumn{4}{|l|}{ Apgar score 5 minute: } \\
\hline$\geq 7$ good score & $153(97.4 \%)$ & $124(99.2 \%)$ & 0.269 \\
\hline$<7$ poor score & $4(2.6 \%)$ & $1(0.8 \%)$ & \\
\hline Respiratory distress & $28(17.8 \%)$ & $9(7.2 \%)$ & $0.009 *$ \\
\hline NICU admission & $22(14 \%)$ & $6(4.8 \%)$ & $0.01 *$ \\
\hline $\begin{array}{l}\text { Endotracheal } \\
\text { intubation/Ambu }\end{array}$ & $15(9.6 \%)$ & $2(1.6 \%)$ & $0.005 *$ \\
\hline Mechanical ventilation & $6(3.82 \%)$ & $0(0 \%)$ & $0.027 *$ \\
\hline Early neonatal death & $2(1.3 \%)$ & $0(0 \%)$ & 0.581 \\
\hline Meconium aspiration & $3(1.9 \%)$ & $6(4.8 \%)$ & 0.17 \\
\hline
\end{tabular}

Abbreviations: NICU Neonatal Intensive Care Unit.

$*$ Significant if $p$-value is $<0.05$.

Preterm labor was identified as the major risk factor, constituting $38.85 \%$ of risk factors and $21.63 \%$ of all deliveries. There were $51(28.17 \%)$ cases that had previous Caesarean Section. Twenty three cases had pregnancy induced hypertension $(14.65 \%)$ and 6 of them where associated with preterm labor $(25 \%)$. Other risk factors found were preterm pre-labor rupture of membranes $13(7.18 \%)$ and antepartum haemorrhage $13(7.18 \%)$, gestational diabetes mellitus 8 (4.42\%). Seven cases (3.87\%) had a history of infertility and assisted reproduction treatment. Other less frequent risk factors comprised 38 cases (20.99\%) as Systemic Lupus Erythrematosis (5 cases), cardiac disease (3 cases), HELLP Syndrome (3 cases), Thrombocytopenia (3 cases), and other risk factor are demonstrated in Fig. (2).

Regarding the neonatal data, in the high risk group males and female percentages were $57 \%$ and $42 \%$ while in low risk group they were $52.8 \%$ and $47.2 \%$ respectively. The neonatal weight was significantly different between the two groups $(p<0.001)$. The Apgar score at 1 minute was poor $(<7)$ in $29.3 \%$ and $24.8 \%$ in the high and low risk groups respectively. Also for poor 5 minute score, $2.55 \%$ and $0.8 \%$ were encountered in high and low risk groups respectively. Preterm labor significantly affected the neonatal weight $(p<0.005)$, Apgar score at 1 minute $(p<0.001)$ but significant effect on Apgar score at 5 minutes. Significant differences 
in the rates of respiratory distress, admission at NICU, ETT and ventilation were found between the two groups as shown in Table (2).

Compared to low risk group, crude relative risk of different neonatal outcomes in the five major risk factor groups are shown in Table (3). Preterm labor was associated with 8.2-fold increased risk of LBW, 1.85-fold increased risk of poor Apgar score at one minute, 5.13 fold increased risk of respiratory distress, 6.83 increased risk of admissions at NICU. Together with PIH each had an increased risk of mechanical ventilation; 26 folds.
The highest risk of mechanical ventilation was associated with antepartum hemorrhage ( 27 folds) than low risk group. The risk for endotracheal intubation was $15.37,9.62$ and 8.15 folds increase in cases with preterm labor, PROM and PIH respectively.

The two neonatal deaths $(1.27 \%)$ in the high risk group were of preterm labor; one with maternal brain tumor and the other was a consequence of PROM. No neonatal mortality in the low risk group was found.

Table (2): Frequency of different neonatal outcomes in low risk and the five major risk factor groups.

\begin{tabular}{|c|c|c|c|c|c|c|c|c|}
\hline Variable & $\begin{array}{l}\text { LBW } \\
\mathrm{N}(\%)\end{array}$ & $\begin{array}{c}\text { Poor Apgar } \\
1 \text { minute } \\
\mathrm{N}(\%)\end{array}$ & $\begin{array}{c}\text { Poor Apgar } \\
5 \text { minute } \\
N(\%)\end{array}$ & $\begin{array}{l}\text { MAS } \\
\mathrm{N}(\%)\end{array}$ & $\begin{array}{c}\text { Respiratory } \\
\text { distress } \\
\mathrm{N}(\%)\end{array}$ & $\begin{array}{c}\text { NICU } \\
\text { admission } \\
\mathrm{N}(\%)\end{array}$ & $\begin{array}{c}\text { ETT } \\
\text { N }(\%)\end{array}$ & $\begin{array}{c}\text { Mechanical } \\
\text { Ventilation } \\
\text { N }(\%)\end{array}$ \\
\hline Low risk & $8(6.4)$ & $31(24.8)$ & $1(0.8)$ & $6(4.8)$ & $9(7.2)$ & $6(4.8)$ & $2(1.6)$ & $0(0)$ \\
\hline Preterm labour & $32(52.46)$ & $28(45.9)$ & $1(1.64)$ & 0 & 24 (39.34) & $20(32.79)$ & $15(24.59)$ & $6(9.84)$ \\
\hline Previous CS & $1(1.96)$ & $8(15.69)$ & $0(0)$ & $1(1.96)$ & $3(5.88)$ & $2(3.92)$ & $1(1.96)$ & $1(1.96)$ \\
\hline $\begin{array}{l}\text { Pregnancy induced } \\
\text { hypertension }\end{array}$ & $6(26.08)$ & $6(26.08)$ & $0(0)$ & $0(0)$ & $4(17.39)$ & $3(13.04)$ & $3(13.04)$ & $2(8.7)$ \\
\hline $\begin{array}{l}\text { Preterm rupture of } \\
\text { membranes }\end{array}$ & $2(15.38)$ & $5(38.46)$ & $1(7.69)$ & $1(7.69)$ & $2(15.38)$ & $2(15.38)$ & $2(15.38)$ & $0(0)$ \\
\hline $\begin{array}{l}\text { Antepartum } \\
\text { Hemorrhage }\end{array}$ & $2(15.38)$ & $3(23.08)$ & $0(0)$ & $0(0)$ & $3(23.08)$ & $1(7.69)$ & $1(7.69)$ & $1(7.69)$ \\
\hline
\end{tabular}

Abbreviations: N: number. LBW: Low birth weight. MAS: Meconium Aspiration Syndrome. ETT: Endotracheal intubation.

NICU: Neonatal Intensive Care Unit.

Table (3): Relative Risk and confidence intervals of different neonatal outcomes in the five major risk factor groups compared to low risk group.

\begin{tabular}{|c|c|c|c|c|c|c|c|c|}
\hline & $\begin{array}{c}\mathrm{LBW} \\
\mathrm{RR}(\mathrm{CI})\end{array}$ & $\begin{array}{l}\text { APGAR at } \\
1 \text { minute } \\
\text { RR }(\mathrm{CI})\end{array}$ & $\begin{array}{l}\text { APGAR at } \\
5 \text { minute } \\
\text { RR (CI) }\end{array}$ & $\begin{array}{c}\text { MAS } \\
\text { RR (CI) }\end{array}$ & $\begin{array}{c}\text { Respiratory } \\
\text { distress } \\
\text { RR }(\mathrm{CI})\end{array}$ & $\begin{array}{c}\text { NICU } \\
\text { admission } \\
\text { RR }(\mathrm{CI})\end{array}$ & $\begin{array}{c}\text { ETT } \\
\text { RR (CI) }\end{array}$ & $\begin{array}{c}\text { Mechanical } \\
\text { Ventilation } \\
\text { RR (CI) }\end{array}$ \\
\hline Preterm labour & $\begin{array}{l}8.2 \\
(4.02-16.7) \\
p<0.0001 *\end{array}$ & $\begin{array}{l}1.85 \\
(1.23-2.79) \\
p 0.003^{*}\end{array}$ & $\begin{array}{l}2.05 \\
(0.13-32.21) \\
p 0.610\end{array}$ & $\begin{array}{l}0.16 \\
(0.009-2.7) \\
p 0.204\end{array}$ & $\begin{array}{l}5.13 \\
(2.53-10.38) \\
p<0.0001^{*}\end{array}$ & $\begin{array}{l}6.83 \\
(2.89-16.13) \\
p<0.0001^{*}\end{array}$ & $\begin{array}{l}15.37 \\
(3.63-65.08) \\
p 0.0002^{*}\end{array}$ & $\begin{array}{l}26.42 \\
(1.51-461.5) \\
p 0.025^{*}\end{array}$ \\
\hline $\begin{array}{l}\text { Previous caesarean } \\
\text { section }\end{array}$ & $\begin{array}{l}0.31 \\
(0.04-2.39) \\
p 0.26\end{array}$ & $\begin{array}{l}0.6 \\
(0.31-1.28) \\
p 0.203\end{array}$ & $\begin{array}{l}0.8 \\
(0.03-19.5) \\
p 0.895\end{array}$ & $\begin{array}{l}0.4 \\
(0.05-3.31) \\
p 0.402\end{array}$ & $\begin{array}{l}0.82 \\
(0.23-2.9) \\
p 0.754\end{array}$ & $\begin{array}{l}0.82 \\
(0.17-3.91) \\
p 0.800\end{array}$ & $\begin{array}{l}1.23 \\
(0.11-13.22) \\
p 0.867\end{array}$ & $\begin{array}{l}7.27 \\
(0.3-175.56) \\
p 0.222\end{array}$ \\
\hline $\begin{array}{l}\text { Pregnancy induced } \\
\text { hypertension }\end{array}$ & $\begin{array}{l}4.08 \\
(1.56-10.65) \\
p 0.004^{*}\end{array}$ & $\begin{array}{l}1.05 \\
(0.50-2.23) \\
p 0.895\end{array}$ & $\begin{array}{l}1.75 \\
(0.07-41.69) \\
p 0.729\end{array}$ & $\begin{array}{l}0.4 \\
(0.024-6.93) \\
p 0.532\end{array}$ & $\begin{array}{l}2.42 \\
(0.81-7.19) \\
p 0.113\end{array}$ & $\begin{array}{l}2.72 \\
(0.73-10.1) \\
p 0.136\end{array}$ & $\begin{array}{l}8.15 \\
(1.44-46.13) \\
p 0.018^{*}\end{array}$ & $\begin{array}{l}26.25 \\
(1.3-529.82) \\
p 0.033^{*}\end{array}$ \\
\hline $\begin{array}{l}\text { Preterm rupture of } \\
\text { membranes }\end{array}$ & $\begin{array}{l}2.4 \\
(0.57-10.15) \\
p 0.232\end{array}$ & $\begin{array}{l}1.55 \\
(0.73-3.29) \\
p 0.253\end{array}$ & $\begin{array}{l}9.6 \\
(0.64-144.86) \\
p 0.102\end{array}$ & $\begin{array}{l}1.6 \\
(0.21-12.31) \\
p 0.650\end{array}$ & $\begin{array}{l}2.14 \\
(0.52-8.86) \\
p 0.295\end{array}$ & $\begin{array}{l}3.2 \\
(0.72-14.29) \\
p 0.127\end{array}$ & $\begin{array}{l}9.62 \\
(1.47-62.7) \\
p 0.018 *\end{array}$ & $\begin{array}{l}9 \\
(0.19-436.22) \\
p 0.267\end{array}$ \\
\hline $\begin{array}{l}\text { Antepartum } \\
\text { Hemorrhage }\end{array}$ & $\begin{array}{l}2.4 \\
(0.57-10.15) \\
p 0.232\end{array}$ & $\begin{array}{l}0.93 \\
(0.33-2.63) \\
p 0.892\end{array}$ & $\begin{array}{l}3 \\
(0.13-70.2) \\
p 0.495\end{array}$ & $\begin{array}{l}0.69 \\
(0.04-11.65) \\
p 0.799\end{array}$ & $\begin{array}{l}3.21 \\
(0.99-10.38) \\
p 0.052\end{array}$ & $\begin{array}{l}1.6 \\
(0.21-12.31) \\
p 0.650\end{array}$ & $\begin{array}{l}4.81 \\
(0.47-49.49) \\
p 0.187\end{array}$ & $\begin{array}{l}27 \\
(1.15-631.76) \\
p 0.041^{*}\end{array}$ \\
\hline
\end{tabular}

Abbreviations: N: Number. CI: Confidence Interval. RR: Relative Risk. ETT: Endotracheal intubation. LBW: Low birth weight.

MAS: Meconium Aspiration Syndrome. NICU: Neonatal Intensive Care Unit.

* Significance at $p<0.05$. 


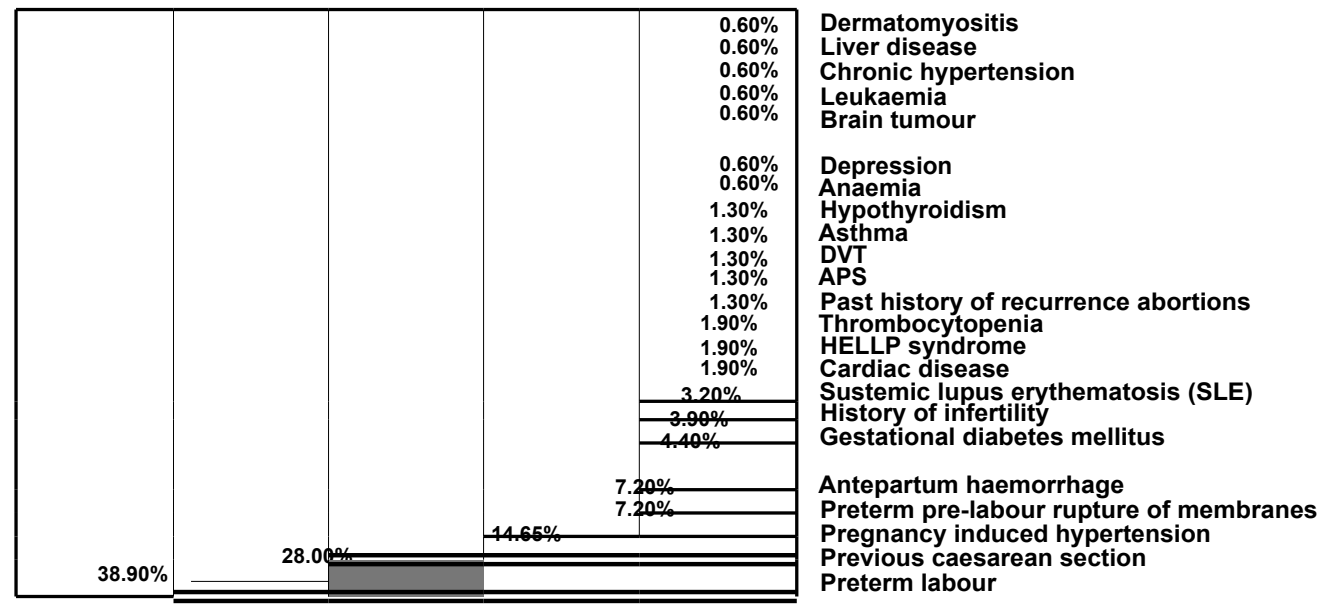

Fig. (2): The percentages of the different risk factors identified in the studied population.

DVT: Deep venous thrombosis. APS: Antiphoapholipid syndrome.

\section{Discussion}

The study was conducted in a tertiary care hospital, where most of the patients were referred from other health care centers and thus belonged mostly to the high risk group. In the current study, perinatal morbidity was more obvious in high risk group than in the low risk group. Significant difference was detected in birth weight, respiratory distress, admission at NICU, endotracheal intubation and mechanical ventilation. The main determinants of poor neonatal outcome in our study was prematurity [61 cases (38.9\%)], followed by previous caesarean section (51 cases $(28 \%)$ ) and PIH was in the third place [23 cases $(13.3 \%)$ ]. Compared to a similar study performed on 282 patients to determine the perinatal outcome of high risk pregnancies, anemia, hypertensive disorders of pregnancy and preterm labor were the main causes in the high risk group for adverse neonatal outcome with percentages of $60.49 \%, 14.8 \%$ and $16 \%$ respectively [19]. While another study aimed at reviewing the extents and determinants of perinatal mortality and included 7743 deliveries, identified antepartum hemorrhage in $20 \%$ and hypertensive disorders in $24 \%$ as the most frequent high risk factors. This study also was carried out in a referral teaching hospital over one year in a third world country; Pakistan [20].

Further analysis of the preterm cases revealed that 35 cases $(59.02 \%)$ were associated with other maternal risk factor; the most frequent was pregnancy induced hypertension (25\%). In severe preeclampsia, decision for termination of pregnancy no later than 34 weeks may explain this association. Even in mild pre-eclampsia, almost one fourth of patients $(25.5 \%)$, had iatrogenic elective latepreterm deliveries [21]. The association of hyper- tensive disorders of pregnancy with increased incidence of preterm delivery was determined to be of $46.6 \%$ in an Indian study [22]. In cases with preterm labor, the Relative Risk (RR) of LBW, poor Apgar score at 1 minute, respiratory distress, NICU admission, ETT and need for mechanical ventilation was $8.2,1.85,5.13,6.83,15.37$ and 26.42 (at $p<0.05$ ) respectively which emphasizes that prematurity greatly affected most of studied early neonatal outcome measures in our study.

In cases with previous section, The RR of LBW, poor Apgar score at 1 and 5 minutes, respiratory distress, NICU admission was lower than the low risk group. In the WHO survey in 2005 on maternal and perinatal health, there was a trend towards a decreased odds ratio for fetal death in elective cesarean section among cases with cephalic presentation (OR $0.65 ; 95 \%$ CI 0.43 to 0.98 ) and a higher prophylactic effect with breech presentation [23]. Data of the Cesarean Section Registry by the Maternal Fetal Medicine Units Network (MFMU) supported previously published records on higher incidence of RDS in newborns of elective repeat cesarean section (ERCS) versus newborns by vaginal birth after cesarean (VBAC). The Registry of MFMU tracked term infants who had an ERCS without any trial of labor, as compared with infants delivered successfully by VBAC. Among ERCS newborns, $6.2 \%$ had respiratory distress and $11.1 \%$ needed NICU admission, compared with $3.3 \%$ respiratory distress and 7.5\% NICU admissions in VBAC group [24]. Another study didn't report cases of neonatal mortality or morbidity among cases with previous caesarean sections, in both elective and emergency caesarean sections [19]. This was in contrast to a large-scale, prospective cohort study from the US, in which 30 ( 2 per 1000 ) term antepartum stillbirths among 15,334 women who 
had undergone VBAC and 12 (0.8 per 1000) among 15,013 having a planned ERCS. As planned caesarean section reported a 5-fold risk of transient tachypnea of newborn or RDS, the absolute risk of neonatal respiratory morbidities associated with term, planned caesarean section was in the range of 3-4\% [25]. The results of the current study being small sampled can't be compared with this large scaled study.

In PROM cases, $38.46 \%$ had LBW, $15.38 \%$ NICU admissions, $15.38 \%$ had respiratory distress and no cases required mechanical ventilation. These results were consistent with those of Sharma et al., where $34.7 \%$ had LBW, $15.3 \%$ NICU admissions $6.9 \%$ had respiratory distress and $2.7 \%$ required mechanical ventilation [13] .

Antepartum hemorrhage (APH) was found in $7.2 \%$ of patients of which the cause was placenta previa in $69.23 \%$ and placental abruption in $30.77 \%$. Compared to the study of Majumder et al, the incidence of APH was $3.8 \%$ where $66 \%$ of cases were of placenta praevia and $34 \%$ were of placental abruption [26]. Among this group, there was 27 fold increase in mechanical ventilation need reflecting the serious condition of the neonate as a cause of perinatal mortality $[\mathbf{2 6 , 2 7 , 2 8}]$. The higher incidence of APH in our study compared to this study could be attributed to early marriage, repeated pregnancies at short intervals and advanced maternal age [29].

The mean maternal age observed in high risk group was slightly higher than the low risk group (32 vs 31.92), with no statistical significance ( $p$ 0.881 ) but $17.05 \%$ of patients with age greater than 35 years delivered low birth weight babies and this was higher percentage compared to a similar study $(11.11 \%)$ [19,25]

\section{Limitations:}

Our study's limitations included the exclusion of multiple gestations inspite being a major contributor to prematurity as other risk factors are considered more important. The study did not extend to long term postnatal effects. Also, considering the prospective analytical design, there was variabilities in population on socio-economic status and education level. Finally, being conducted in a tertiary level referral hospital our results cannot be generalized.

\section{Conclusion:}

Neonatal morbidity was higher in high risk group compared to low risk group. The difference was significant in birth weight, respiratory distress,
NICU admission, endotracheal intubation and mechanical ventilation. The highest risk was significant with preterm delivery followed by previous caesarean section then pregnancy induced hypertension.

\section{Recommendations:}

Early identification and aggressive management of high risk pregnancy are crucial in the care of pregnant women to ensure best possible outcome for both mother and baby as their outcomes are closely linked and it can reduce the early neonatal complications. Special care should be targeted to preterm pregnancy risk factors, pregnancies with previous cesarean section and hypertensive pregnancies.

\section{Funding:}

This research did not receive any specific grant from funding agencies in the public, commercial, or not-for-profit sectors.

\section{Declaration of interest: None.}

\section{Practice points:}

- A careful and detailed history is required to recognize high risk factors that can have deleterious effect on both maternal and fetal outcomes.

- Preventive measures of risk factors that lead to high risk pregnancy as proper health education and regular antenatal visits.

- Proper and timely management of high risk pregnancy could positively affect early neonatal outcome.

- Perinatal morbidities were higher in high risk pregnancies compared to low risk group.

- Our study calculated the Relative Risk of low birth weight, poor Apgar score at 1 minute, respiratory distress, neonatal intensive care unit admission, endotracheal intubation and mechanical ventilation and found these risks significantly higher in preterm deliveries emphasizing that prematurity affected early neonatal outcomes.

- This study identified and ordered the main determinants of poor neonatal outcomes to be preterm delivery, previous cesarean section and hypertensive disorders respectively.

\section{Further research:}

- Further studies on a larger scale, longer duration and multicenter location might be needed.

- An extended study (longitudinal) might help to identify long term postnatal effects. 


\section{References}

1- ARIAS F.: Birth asphyxia. In: Arias F. (ed). Practical guide to high risk pregnancy and delivery. edi. Philadelphia: Elsevier, 413-29, 2004.

2- The Central Agency for Public Mobilization and Statistics (Egypt), and UNICEF Egypt (2017). Children in Egypt: a statistical digest. Cairo, Egypt, 2016.

3- SALEH W.F., RAGAB W.S. and ABOULGHEIT S.S.: Audit of maternal mortality ratio and causes of maternal deaths in the largest maternity hospital in Cairo, Egypt (Kasr Al-Aini) in 2008 and 2009: Lessons learned. Afr. J. Reprod Health, 17: 105-9, 2013.

4- LAWN J.E., COUSENS S.N., DARMSTADT G.L., et al.: 1 year after The Lancet Neonatal Survival Series-was the call for action heard? Lancet, 367: 1541-7, 2006.

5- BECK S., WOJDYLA D., SAY L., et al.: The worldwide incidence of preterm birth: A systematic review of maternal mortality and morbidity. Bull World Health Organ, 88: 31-8. doi: 10.2471/BLT.08.062554, 2010.

5- GOLDENBERG R.L., CULHANE J.F., IAMS J.D., et al. Epidemiology and causes of preterm birth. Lancet, 371 : 75-84. doi: 10.1016/S0140-6736(08)60074-4, 2008.

7- PETROU S.: The economic consequences of preterm birth during the first 10 years of life. BJOG, 112: 10-5, 2005.

8- SIBAI B.M., CARITIS S. and HAUTH J.: National Institute of Child Health and Human Development MaternalFetal Medicine Units Network. What we have learned about preeclampsia. Semin Perinatol., 27: 239-46, 2003.

9- MARTIN J.A., HAMILTON B.E., SUTTON P.D., Menacker F., Kirmeyer S., et al.: Births: Final data for 2005. Natl Vital Stat Rep., 56: 1-103, 2007.

10- ANGUS D.C., LINDE-ZWIRBLE W.T., CLERMONT G., et al.: Epidemiology of neonatal respiratory failure in the United States: Projections from California and New York. Am. J. Respir. Crit Care Med., 164: 1154-60, 2001.

11-ROTH-KLEINER M., WAGNER B.P., BACHMANN D., et al.: Respiratory distress syndrome in near-term babies after caesarean section. Swiss Med Wkly, 133: 283-8, 2003.

12-RAMACHANDRAPPA A. and JAIN L.: Elective cesarean section: Its impact on neonatal respiratory outcome. Clin. Perinatol., 35:373-93.doi: 10.1016/j.clp.2008.03.006, 2008.

13- EL-MESSIDI A. and CAMERON A.: Diagnosis of premature rupture of membranes: Inspiration from the past and insights for the future. J. Obstet. Gynaecol. Can., 32:561-9.doi: 10.1016/S1701-2163(16)34525-X, 2010.

14-MEDINA T.M. and HILL D.A.: Preterm premature rupture of membranes: Diagnosis and management. Am. Fam. Physician., 73: 659-64, 2006.

15- SHARMA S.K. and DEY M.: Maternal and neonatal outcome in cases of premature rupture of membranes beyond 34 weeks of gestation. Int. J. Reprod Contracept Obstet. Gynecol., 6: 1302-5. doi: 10.18203/23201770.ijrcog20171382, 2017.
16- FREDERIKSEN M.C., GLASSENBERG R. and STIKA C.S.: Placenta previa: A 22-year analysis. Am. J. Obstet. Gynecol., 180: 1432-7, 1999.

17-ANANTH C.V., SMULIAN J.C. and VINTZILEOS A.M.: Incidence of placental abruption in relation to cigarette smoking and hypertensive disorders during pregnancy: A meta-analysis of observational studies. Obstet. Gynecol., 93: 622-8, 1999.

18- CUNNINGHAM F., LEVENO K., BLOOM S., et al.: Obstetrical haemorrhage. In: Williams Obstetrics. (23 rd ed), New York, McGraw Hill Professionals, 2009.

19- ZAREEN N., NAQVI S., MAJID N., et al.: Perinatal outcome in high risk pregnancies. J. Coll. Physicians Surg. Pak., 19:432-5.doi: 07.2009/JCPSP.432435, 2009.

20- KOREJO R., BHUTTA S., NOORANI K.J., et al.: An audit and trends of perinatal mortality at the Jinnah Postgraduate Medical Centre, Karachi. J. Pak. Med. Assoc., 57: 168-72, 2007.

21- BARTON J.R., BARTON L.A., ISTWAN N.B., et al.: Elective delivery at $340 / 7$ to $366 / 7$ weeks' gestation and its impact on neonatal outcomes in women with stable mild gestational hypertension. Am. J. Obstet. Gynecol., 204: 44.e1-e5. doi:10.1016/j.ajog.2010.08.030, 2011.

22- DODDAMANI G.B. and DODDAMANI U.G.: Perinatal Outcome in Pre-Eclampsia: A Prospective Study. Sch. J. App. Med. Sci., 2: 291-3, 2014.

23- VILLAR J., CARROLI G., ZAVALETA N., et al.: Maternal and neonatal individual risks and benefits associated with caesarean delivery: Multicentre prospective study. BMJ, 335:1025, 2007.

24- JAIN L. and EATON D.C.: Physiology of fetal lung fluid clearance and the effect of labor. Semin Perinatol., 30: 34-43, 2006.

25- STUDD J.: Progress in obstetrics and gynaecology, 17 th ed. Edinburgh: Churchill Livingstone, 2006.

26- MAJUMDER S., SHAH P.T., DELIWALA K.J., et al.: Study of foetomaternal outcome of antepartum haemorrhage in pregnancy. Int. J. Reprod Contracept Obstet. Gynecol., 4: 1936-9.doi: 10.18203/2320-1770.ijrcog 20151289, 2017.

27- KEDAR K., UIKEY P., PAWAR A., et al.: Maternal and fetal outcome in antepartum haemorrhage: A study at tertiary care hospital. Int J ReprodContraceptObstet Gynecol., 5: 1386-91.doi: 10.18203/2320-1770.ijrcog 20161291, 2017.

28- TAKAI I.U., SAYYADI B.M. and GALADANCI H.S. Antepartum hemorrhage: A retrospective analysis from a northern nigerian teaching hospital. Int. J. App. Basic Med. Res., 7 (2): 112-16.doi: 10.4103/2229-516X.205819, 2017.

29- BIRO M.A., DAVEY M.A., CAROLAN M., et al.: Advanced maternal age and obstetric morbidity for women giving birth in Victoria, Australia: A population based study. Aust. NZJ Obstet. Gynaecol., 52:229-34.doi: 10. 111 1/j. 1479-828X.2012.01427.x, 2012. 


\section{تتائج حلديثى الولادة فى حالات الحمل عالية الرماية الخطورة

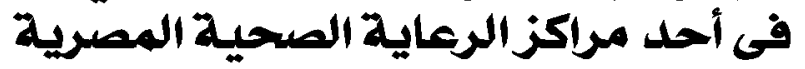

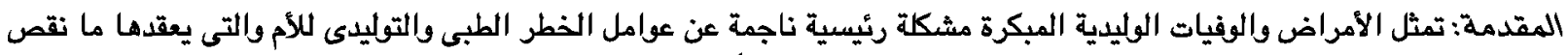

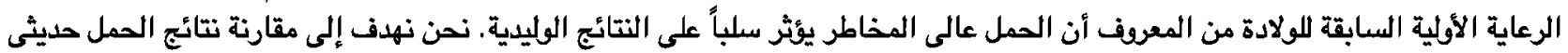

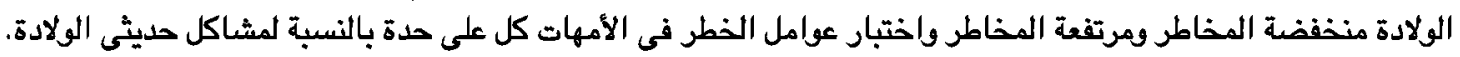

تصميم الدراسة والطرق : أجريث دراسة استعادية في مستشفى الإحالة العالى أكثر من 7 أشهر . بعد تطبيق معايير الأهلية، تم تصديل

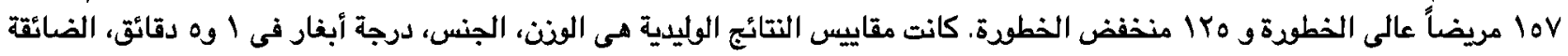

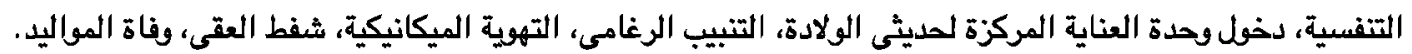

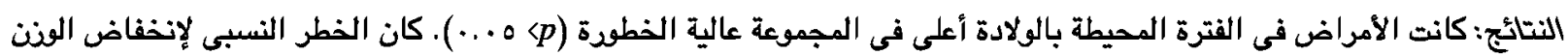

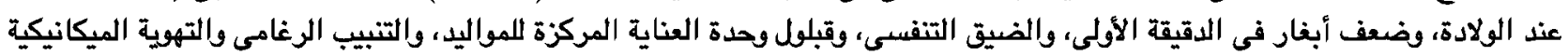

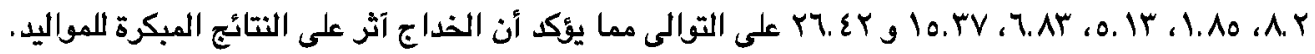
الخلاصة: كانت المصدات الرئيسية لنتائج حديثى الولادة المبكرة، الولادة القيصرية السابقة واضطرابات ارتفاع ضغط الدم. 